\title{
Effect of Different Finishing/Polishing Systems on the Surface Roughness of Two Heat-Treated Composite Resins
}

\author{
Gabrielle Ribeiro Lima*, Nathalia Cardoso Baima Maluf ${ }^{\text {a }}$, Soraia de Fátima Carvalho Souza , \\ Antonio Ernandes Macedo Paiva ${ }^{\text {b }}$ Erick Miranda Souza ${ }^{\mathrm{c}}$, Ivone Lima Santana ${ }^{\mathrm{a}}$ \\ ${ }^{a}$ School of Dentistry, Federal University of Maranhão, São Luís, MA, Brazil \\ ${ }^{\mathrm{b}}$ Department of Materials Science, Maranhão Federal Center for Technological Education, \\ São Luís, MA, Brazil \\ ${ }^{c}$ School of Dentistry, Maranhão University Center, São Luís, MA, Brazil
}

Received: July 11, 2010; Revised: April 19, 2011

\begin{abstract}
The aim of this study was to compare the surface roughness achieved by different finishing/polishing systems on two composite resins for direct use after thermic treatment. The specimens ( $\mathrm{n}=40$ per group $(\mathrm{G}) ; \mathrm{G} 1=\mathrm{Filtek}^{\mathrm{TM}}$ P60; G2 $=$ Fill Magic $\left.^{\circledR}\right)$ were set up on a matrix of stainless steel with circular internal niches $(\varnothing=10.0 \mathrm{~mm}$; $\mathrm{h}=2.0 \mathrm{~mm}$ ). Next, they were subjected to thermal treatment in a heated chamber at $170{ }^{\circ} \mathrm{C}$ for 10 minutes. They were then divided randomly into four subgroups $(\mathrm{Sg})$ to receive the surface treatment according to the finishing/ polishing systems tested $(\mathrm{n}=10)$ : Sg A: Control; Sg B: Diamond ${ }^{\circledR}$ felt disc + Diamond Excel ${ }^{\circledR}$ diamond paste; Sg C: Sof-Lex ${ }^{\circledR}$ discs; and Sg D: Enhance ${ }^{\mathrm{TM}}$ silicon tips. The mean roughness (Ra) was determined using a digital surface roughnes tester. Data was analyzed by two-way ANOVA and Tukey's post-hoc test $(\alpha=0.05)$. Differences between the surface treatments were found on both resins $(p<0.05)$. In $\mathrm{G} 1$, the lowest mean Ra values were observed using $\operatorname{Sg~C}(0.07 \mu \mathrm{m})$ and the highest for $\operatorname{Sg} \mathrm{D}(0.12 \mu \mathrm{m})(\mathrm{p}<0.05)$. There was no difference between $\mathrm{Sg} \mathrm{B}(0.08 \mu \mathrm{m})$ and $\mathrm{Sg} \mathrm{C}(0.07 \mu \mathrm{m})(\mathrm{p}=0.076)$. In $\mathrm{G} 2$, there was a progressive increase in mean Ra values from $\mathrm{Sg} \mathrm{D}(0.05 \mu \mathrm{m})$ to $\mathrm{Sg} \mathrm{C}(0.06 \mu \mathrm{m})$ and to $\mathrm{Sg} \mathrm{B}(0.07 \mu \mathrm{m})(\mathrm{p}<0.05)$. It was concluded that the finishing/polishing systems modified $\mathrm{Ra}$ on both resins.
\end{abstract}

Keywords: composite resins, dental polishing, heat treatment

\section{Introduction}

Since the increasing value placed on esthetic facial harmony, cosmetic dentistry has evolved to make it possible to perform direct restorations that are esthetically more desirable and cavity preparations that preserve tooth structures. Improvements on the physical, mechanical and chemical properties of composite resins have enabled their use not only in anterior teeth but also in posterior teeth ${ }^{1}$.

However, certain clinical problems associated with the use of direct composite resins have been seen. Among them there is the surface roughness of the restoration ${ }^{2,3}$. The difficulty in achieving a smooth and shiny surface through finishing and polishing the restoration is of concern. This occurs mainly due to (1) the size, consistency and quantity of the composite applied, and (2) the hardness and grain size of the abrasive used ${ }^{3,4}$. A rough surface allows dental plaque to stick to it and secondary caries and periodontal disease $^{5}$, and restoration marginal discoloration ${ }^{6-8}$.

Another critical factor in performing a restoration using the direct technique with composite resins is polymerization shrinkage ${ }^{9}$. This phenomenon induces the formation of marginal gaps, resulting in microleakage. Clinically, postoperative sensitivity may occur ${ }^{10}$. It is likely to be worse in large cavities in posterior teeth, which would limit the use of the direct technique. For such cases, the indirect technique seems to provide certain clinical benefits, such as rebuilding the anatomical shape of the tooth, improving the adaptation of the edges of the filling (especially in relation to the gingival wall) and restoring the proximal contacts that had been destroyed by caries ${ }^{11}$.
In essence, the composites for direct and indirect use have similar compositions, because it is believed that by means of simple technical modifications such as additional heat treatment ${ }^{12}$, direct composites may attain levels of mechanical resistance that are similar to those of systems for indirect use, even without the use of special equipment ${ }^{13}$. Secondary polymerization through thermal treatment is a method used to increase the degree of conversion of composites. Scientific evidence indicates that the use of this method improves physical properties of these materials ${ }^{9,14-16}$.

Considering that there is little information about the effects of heat treatment on composite resins for direct use, the aim of this study was to compare the influence of different finishing/polishing systems on the surface of two commercial heat treated composite resins. The hypothesis to be tested was that there is no difference in surface roughness between the materials when subjected to the different types of surface treatments tested.

\section{Material and Methods}

\subsection{Specimen preparation}

Two commercial direct composites microhybrid resin Fill Magic ${ }^{\circledR}$ (Vigodent, Bom Sucesso, Rio de Janeiro, Brazil) and hybrid resin Filtek $^{\mathrm{TM}}$ P60 (3M ESPE, St Paul, MN, USA) were used as seen in Table 1. 
Table 1. Composites descriptions used in the study.

\begin{tabular}{|c|c|c|c|}
\hline Material & Manufacturer & Composition & Batch \\
\hline Filtek $^{\mathrm{TM}} \mathrm{P} 60$ & 3 M ESPE, St Paul, MN, USA & $\begin{array}{l}\text { Aluminum oxide, zirconium dioxide and silica } 61 \% \text { by volume, with } \\
\text { grain sizes } 0.19 \text { to } 3.3 \mu \mathrm{m} \text {. Organic matrix composed of BIS-GMA, } \\
\text { UDMA and BIS-EMA. }\end{array}$ & $7 \mathrm{RR}$ \\
\hline Fill Magic ${ }^{\circledR}$ & $\begin{array}{l}\text { Vigodent S.A. Ind. Com., Bom } \\
\text { Sucesso, Rio de Janeiro, Brazil }\end{array}$ & $\begin{array}{l}\text { Metacrylic monomers, pyrogenic silica, barium silicate and aluminum } \\
\text { silicate } 80 \% \text { in barium glass, with grain size } 0.5 \mu \mathrm{m} \text {. Organic matrix } \\
\text { composed of Bis-GMA, TEGDMA, Bis-EMA and UDMA. }\end{array}$ & $187 / 07$ \\
\hline
\end{tabular}

Table 2. Description of the finishing/polishing systems used in the study.

\begin{tabular}{|c|c|c|c|c|}
\hline Material & Manufacturer & Grain size & Composition & Batch \\
\hline Diamond Excel ${ }^{\circledR}$ & $\begin{array}{l}\text { FGM Ind. Brasileira, } \\
\text { Joinville, SC, Brazil }\end{array}$ & $2-4 \mu \mathrm{m}$ & $\begin{array}{c}\text { Micronized diamond, lubricating substrate, } \\
\text { thickener and emulsifier }\end{array}$ & 300707 \\
\hline Diamondflex $^{\circledR}$ & $\begin{array}{l}\text { FGM Ind. Brasileira, } \\
\text { Joinville, SC, Brazil }\end{array}$ & - & Natural felt and silicone rubber & 823137 \\
\hline Enhance $^{\mathrm{TM}}$ & $\begin{array}{l}\text { Dentsply Indústria e } \\
\text { Comércio Ltda. }\end{array}$ & $40 \mu \mathrm{m}$ aluminum oxide & $\begin{array}{c}\text { Tripolymer, silanized pyrolytic silica, urethane } \\
\text { dimethacrylate, camphorquinone, } \mathrm{N} \text {-methyl } \\
\text { diethanolamine and aluminum oxide }\end{array}$ & $123 / 04$ \\
\hline Sof-Lex ${ }^{\circledR}$ & $\begin{array}{l}\text { 3M do Brasil Ltda, } \\
\text { Sumaré, SP, Brazil }\end{array}$ & $\begin{array}{l}\text { Medium }-29 \mu \mathrm{m} \\
\text { Fine }-14 \mu \mathrm{m} \\
\text { Ultrafine }-5 \mu \mathrm{m}\end{array}$ & Aluminum oxide & 19085 \\
\hline
\end{tabular}

The specimens were prepared ( $n=40$ per group) using a stainless steel matrix ( $10 \mathrm{~mm}$ width $\times 2 \mathrm{~mm}$ height). The resins were inserted into the matrix in two increments. Each increment was light cured using LED laser (Dabi Atlante Ultraled, Ribeirão Preto, São Paulo, Brazil) at $600 \mathrm{~mW} \cdot \mathrm{cm}^{-2}$ for 40 seconds $\left(24 \mathrm{~J} . \mathrm{cm}^{-2}\right)$. A strip of polyester of thickness $0.005 \mathrm{~mm}$ (Labordental Ltda., São Paulo, SP, Brazil) was positioned over the last resin layer and a glass slide was pressed onto this to remove any excess material. Then, the surface of the specimen was light cured again as previously described.

All the specimens were dry heated (Ética Equipamentos Científicos SA, São Paulo, Brazil), at a temperature of $170{ }^{\circ} \mathrm{C}$ for 10 minutes, with monitoring using a thermometer (Salvterm 1200K; Salcas Ind. Com. Ltda, São Paulo, Brazil), in accordance with a previous studies ${ }^{9-14}$ that determinated the heat treatment temperature, by thermogravimetric analysis and differential scanning calorimetry, considering the initial weight loss temperature and glass transition temperature.

Next, the specimens were removed and kept at room temperature until the material had fully cooled down. It was then stored in distilled water at $37{ }^{\circ} \mathrm{C}$ for 24 hours.

Thereafter, the specimens in each group were randomly assigned to four subgroups $(\mathrm{Sg})$ according to the finishing/polishing systems (Table 2 and Figure 1).

All the systems were used according to manufacturer's instructions and with a low speed handpiece (5000 to $20000 \mathrm{rpm}$ ). The Sof-Lex ${ }^{\circledR}$ discs (3M, Sumaré, SP, Brazil) were used in decreasing order of grain size $(29,14$ and $5 \mu \mathrm{m})$ for 20 seconds; the Enhance ${ }^{\mathrm{TM}}$ silicon tips (Dentsply, Petrópolis, RJ, Brazil) for 30 seconds; and the Diamondflex ${ }^{\circledR}$ felt discs (FGM, Joinville, SC, Brazil) with Diamond Excel $^{\circledR}$ diamond paste (FGM, Joinville, SC, Brazil) for 60 seconds. The finishing/polishing was performed by single operator with low pressure and intermittent movements. The control group consisted of only the use of polyester strip, without finishing / polishing.

\subsection{Surface roughness test}

Surface roughness was measured using a digital surface roughness tester (Surftest 301; Mitutoyo America Corporation, Suzano, SP, Brazil), which was calibrated through a distance of $0.25 \mathrm{~mm}$ on the micrometer scale $(\mu \mathrm{m})$ according to ISO 4287 (International Standards Organization). Six readings were made on each specimen, in two different directions (three vertical and three horizontal). Mean values for surface roughness $(\mathrm{Ra})$ were obtained in micrometers.

\subsection{Statistical analysis}

The data obtained were normally distributed (KolmogorovSmirnoff test) and homoscedastic (Levene test). These data were analyzed by two-way ANOVA and Tukey's post-hoc test at 5\% significance level.

\section{Results}

Two-way ANOVA showed that the means ( $\mathrm{Ra}$ ) obtained from the different surface treatments were statistically different in relation to both resins evaluated $(\mathrm{p}<0.05)$. The means and standard deviations for each subgroup $(\mathrm{Sg})$ of the two experimental groups $(\mathrm{G})$ can be seen in Figure 2. For G1 (Filtek $\left.{ }^{\mathrm{TM}} \mathrm{P} 60\right)$, in Sg D (Enhance ${ }^{\mathrm{TM}}$ tips) the highest mean values $(0,12 \mu \mathrm{m})$ were observed $(\mathrm{p}<0.05)$. There was no difference between $\mathrm{Sg} \mathrm{B}(0,08 \mu \mathrm{m}$, felt disc + diamond paste $)$ and $\operatorname{Sg~C~}(0,07 \mu \mathrm{m})$ (Sof-Lex ${ }^{\circledR}$ disc). The p value was 0.076 . For G2 $\left(\right.$ Fill Magic $\left.{ }^{\circledR}\right)$, there were differences among all the $\mathrm{Sg}(\mathrm{p}<0.05)$, so that $\mathrm{Sg} \mathrm{D}$ had the lowest mean value $(0,05 \mu \mathrm{m})$, followed by $\mathrm{Sg} \mathrm{C}$ $(0,06 \mu \mathrm{m})$ and $\mathrm{Sg} \mathrm{B}(0,07 \mu \mathrm{m})$, respectively.

\section{Discussion}

Based on the results from this in vitro study, the hypothesis was partially rejected. The finishing/polishing systems tested showed 


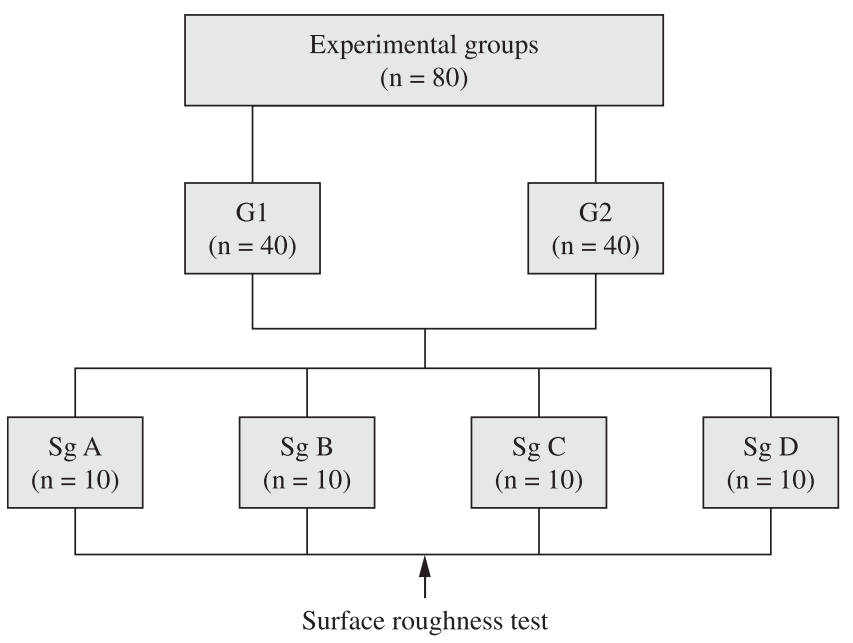

Figure 1. Experimental design. G1 (Group $1=$ Filtek $^{\mathrm{TM}}$ P60); G2 $\left(\right.$ Group $2=$ Fill Magic $\left.^{\circledR}\right)$. Subgroups (Sg): Sg A (Control); Sg B (Diamond $^{\circledR}$ felt disc + Diamond Excel ${ }^{\circledast}$ diamond paste); Sg C (Sof-Lex ${ }^{\circledast}$ discs); Sg D (Enhance ${ }^{\mathrm{TM}}$ silicon tips).

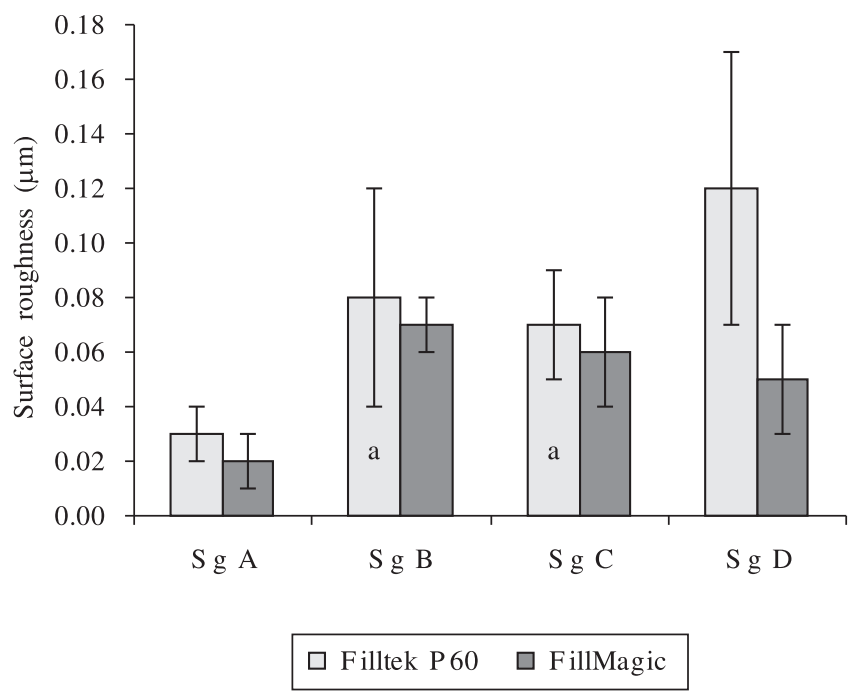

Figure 2. Means and standard deviations for surface roughness obtained using the four finishing/polishing systems on the two resins tested. The same letter inside the bars indicates statistically similar results $(\mathrm{p}>0.05)$.

changes in the smoothness of the surface when compared to the two composites (Filtek ${ }^{\mathrm{TM}}$ P60 and Fill Magic ${ }^{\circledR}$ ). The control groups (polyester matrix) for both resins (G1 Sg A and G2 Sg A) (Figure 2) achieved the lowest mean values for $\mathrm{Ra}$ and differed significantly from all the other finishing/polishing systems tested $(p<0.05)$. These findings were consistent with other studies that also showed lowest mean values for $\mathrm{Ra}$ when used polyester matriz $\mathrm{z}^{6,17-21}$.

In G1 (Filtek ${ }^{\mathrm{TM}}$ P60) (Figure 2), Sg D (Enhance ${ }^{\mathrm{TM}}$ tips, $0.12 \mu \mathrm{m}$ ) presented the highest mean values for Ra compared with $\mathrm{Sg} \mathrm{C}$ (Sof-Lex ${ }^{\circledR}$ discs, $0.07 \mu \mathrm{m}$ ) and Sg B (felt disc + diamond paste, $0.08 \mu \mathrm{m})$, respectively $(\mathrm{p}<0.05)$. Curiously, in G2 (Fill Magic ${ }^{\circledR}$ ) (Figure 2), Sg D demonstrated the lowest mean values for $\mathrm{Ra}$ $(0.05 \mu \mathrm{m})$, compared to $\mathrm{Sg} \mathrm{C}$ and $\mathrm{Sg} \mathrm{B}(0.06$ and $0.07 \mu \mathrm{m})$, respectively $(\mathrm{p}<0.05)$. Lu et al. ${ }^{18}(2003)$ suggested that the interaction between the Filtek ${ }^{\mathrm{TM}} \mathrm{P} 60$ resin and the finishing/polishing system might have been harmed by two factors: 1) the flexibility of the
Enhance $^{\mathrm{TM}}$ tips; and 2) the composition of the inorganic matrix of the resin, formed by larger particles $(0.19$ to $3.3 \mu \mathrm{m})$ that were harder and more irregular.

On the other hand, Reis et al. ${ }^{3}$ (2003) and Scheibe et al. ${ }^{22}$ (2009) evaluated the effectiveness of finishing/polishing systems on the surface of some composite resins, and concluded that the best polishing was achieved using the felt disc + diamond paste. Nevertheless, in this study, the results did not agree with theirs, since the felt disc + diamond paste system showed higher mean values for Ra to the Filtek ${ }^{\mathrm{TM}}$ P60 resin $(0.08 \mu \mathrm{m}, \mathrm{G} 1 \mathrm{Sg}$ B) (Figure 2) than to the Fill Magic ${ }^{\circledR}$ resin $(0.07 \mu \mathrm{m}, \mathrm{G} 2 \mathrm{Sg}$ B) (Figure 2). This fact might be explained by differents composites resins and finishing/polishing systems used.

Smaller mean values for Ra were obtained using Sof-Lex ${ }^{\circledR}$ discs on the Filtek ${ }^{\mathrm{TM}} \mathrm{P} 60$ resin $(0.07 \mu \mathrm{m}, \mathrm{G} 1 \mathrm{Sg}$ C) (Figure 2) than on the Fill Magic ${ }^{\circledR}$ resin $(0.06 \mu \mathrm{m}, \mathrm{G} 2 \mathrm{Sg}$ C) (Figure 2). This result can be also explained because aluminum oxide discs do not displace the composite fillers and the malleability of the discs promotes a homogeneous abrasion of the fillers and resin matrix ${ }^{23}$.

Ferracane et al. ${ }^{24}$ (1995) suggested that Sof-Lex ${ }^{\circledR}$ discs should be used in the proximal surface because of their thinness, and that the felt disc + diamond paste system would be a good choice for the occlusal surfaces of direct composite resin. In this research, the mean values for Ra from Sg B $(0.08 \mu \mathrm{m})$ and $\mathrm{Sg} \mathrm{C}(0.07 \mu \mathrm{m})$ on G1 (Filtek $\left.{ }^{\mathrm{TM}} \mathrm{P} 60\right)$ did not presented any significant differences $(\mathrm{p}=0.076)$.

Additional thermal treatment on direct composite resins is already greatly used due to the observed improvement on physical properties

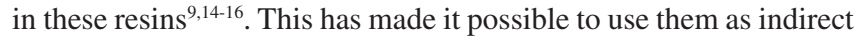
restorations. The possibility of polishing outside of the oral cavity that indirect restorations improves the proximal contact, reduces the strain on the tooth and decrease to polymerization contraction stress, thereby enabling greater control of marginal microleakage and recurrent caries ${ }^{16}$.

Therefore, considering the possibility of offering rehabilitation for posterior teeth to low-income communities at lower cost, which would enable greater social coverage of oral rehabilitation and oral health promotion, it is believed that these laboratory results could be extrapolated for clinical application. However, further studies are needed to evaluate other parameters, such as anatomical shape, marginal integrity and discoloration, which might influence the longevity of these dental restorations.

\section{Conclusion}

This study demonstrated that the finishing/polishing technique with silicon tips produced smoothness surfaces on the microhybrid composite. For hybrid composite, formed by hard and irregular particles, the highest polishing was obtained using aluminum oxide discs.

\section{References}

1. Hickel R and Manhart J. Longevity of restorations in posterior teeth and reasons for failure. Journal of Adhesive Dentistry. 2001; 3(1):45-64. PMid:11317384.

2. Ryba TM, Dunn WJ and Murchison DF. Surface roughness of various packable composites. Operative Dentistry. 2002; 27(3):243-247. PMid: 12022454.

3. Reis AF, Giannini M, Lovadino JR and Ambrosano M. Effects of various finishing systems on the surface roughness and staining susceptibility of packable composite resins. Dental Materials. 2003; 19(1):12-8. doi:10.1016/S0109-5641(02)00014-3 
4. Neme AL, Frazier KB, Roeder LB and Debner TL. Effect of prophylactic polishing protocols on the surface roughness of esthetic restorative materials. Operative Dentistry. 2002; 27(1):50-58. PMid:11817469.

5. Quirynen M and Bollen CML. The influence of surface roughness and surface-free energy on supra and subgingival plaque formation in man. Journal of Clinical Periodontology. 1995; 22(1):1-14. PMid:7706534. doi:10.1111/j.1600-051X.1995.tb01765.x

6. Roeder LB, Tate WH and Powers JM. Effect of finishing and polishing producers on the surface roughness of packable composites. Operative Dentistry. 2000; 25(6):534-543. PMid:11203867.

7. Setcos JC, Tarim B and Suzuki S. Surface finish produced on resin composites by new polishing systems. Quintessence International. 1999; 30(3):169-173. PMid:10356569.

8. Yap AUJ, Yap SH, Teo CK and Ng JJ. Finishing/polishing of composite and compomer restoratives: effectiveness of one-step systems. Operative Dentistry. 2004; 29(3):275-279. PMid:15195727.

9. Santana IL, Lodovici E, Matos JR, Medeiros IS, Miyazaki CL and Rodrigues-Filho LE. Effect of Experimental Heat Treatment on Mechanical Properties of Resin Composites. Brazilian Dental Journal. 2009; 20(3):205-210. PMid:19784465.

10. Roulet JF. Benefits and disadvantages of tooth-caloured alternatives to amalgam. Journal of Dentistry. 1997; 25(6):459-473. doi:10.1016/ S0300-5712(96)00066-8

11. Touati B and Aidan N. Second generation laboratory composite resins for indirect restorations. Journal of Esthetic Dentistry. 1997; 9(3):108-118. doi:10.1111/j.1708-8240.1997.tb00928.x

12. Peutzfeldt $A$ and Asmussen E. Effect of temperature and duration of postcure on selected mechanical properties of resin composites containing carboxylic anhydrides. Scandinavian Journal of Dental Research. 1992; 100(5):296-298. PMid:1411274.

13. Ruyter IE. Types of resin-based inlay materials and their properties. International Dental Journal. 1992; 42(3):139-144. PMid:1500209.

14. Miyazaki CL, Medeiros IS, Santana IL, Matos JR and Rodrigues Filho LE. Heat treatment of a direct composite resin: influence on flexural strength. Brazilian Oral Research. 2009; 23(3):241-247. PMid:19893957. doi: 10.1590/S1806-83242009000300004

15. Reinhardt JW, Boyer DB and Stephens NH. Effects of secondary curing on indirect posterior composite resins. Operative Dentistry. 1994; 19(6):217-220. PMid:9028240.

16. Wendt Jr SL and Leinfelder KF. The clinical evaluation of heat-treated composite resin inlays. Journal of the American Dental Association. 1990; 120(2):177-181. PMid:2299059.

17. Jung M, Hornung $\mathrm{K}$ and Klimek J. Polishing occlusal surfaces of direct class II composite retorations in vivo. Operative Dentistry. 2005 30(2):139-146. PMid:15853097.

18. Lu H, Roeder LB and Powers JM. Effect of polishing systems on the surface roughness of microhybrid composites. Journal of Esthetic and Restorative Dentistry. 2003; 15(5):297-303. PMid:14620660. doi:10.1111/j.1708-8240.2003.tb00300.x

19. Hondrum SO and Fernández Jr R. Contouring, finishing, and polishing class V restorative materials. Operative Dentistry. 1997; 22(1):30-36. PMid:9227125.

20. Chung KH. Effects of finishing and polishing procedures on the surface texture of resin composites. Dental Materials. 1994; 10(5):325-330. doi:10.1016/0109-5641(94)90041-8

21. Tate WH and Powers JM. Surface roughness of composites and hybrid ionomers. Operative Dentistry. 1996; 21(2):53-58. PMid:8957918.

22. Scheibe KGBA, Almeida KGB, Medeiros IS, Costa JF and Alves CMC. Effect of different polishing systems on the surface roughness of microhybrid composites. Journal of Applied Oral Science. 2009; 17(1):21-26. PMid:19148401.

23. Botta AC, Duarte SJr, Paulin Filho PI, Gheno SM and Powers JM. Surface roughness of enamel and four resins composites. American Journal of Dentistry. 2009; 22(5):252-254. PMid:20225464.

24. Ferracane JL. Materials in dentistry: principles and application. Pensylvania: J. B. Lipping Company; 1995. p.133-137. 